\title{
A transfer of control test for contextual associations
}

\author{
JEFF PATTERSON and J. BRUCE OVERMIER \\ University of Minnesota, Minneapolis, Minnesota 55455
}

\begin{abstract}
A transfer of control experiment measured the associative properties of contextual stimuli from three standard classical conditioning paradigms. After baseline training on a Sidman avoidance schedule, dogs received aversive conditioning using excitatory, inhibitory, or truly random conditioning procedures in the presence of a manipulable background stimulus. As predicted by current theory (Rescorla \& Wagner, 1972; Wagner \& Rescorla, 1972), the contextual stimulus was excitatory after serving as the background during conditioning of a CS- and was neutral when it had been part of the background for conditioning of a CS+. The background to the truly random procedure was also neutral. This last result contrasts with Rescorla and Wagner's theory.
\end{abstract}

\begin{abstract}
"Background," “contextual," or "apparatus", stimuli have occupied a prominent position, both theoretically and empirically, in contemporary work on learning processes. McAllister and McAllister (1971) noted that all stimuli contiguous with reinforcement were fair candidates for conditioning and that experimenters must not restrict their attention solely to those that they manipulate. By taking into account contextual stimuli, they were able to explain differences in avoidance acquisition that depend upon the type of apparatus used. Rescorla and Wagner's (1972; Wagner \& Rescorla, 1972) theory achieves part of its remarkable success in predicting classical conditioning results (see LoLordo, 1979, for a review) by assuming that the experimental context may become excitatory. Exposure to random CS and US presentations (Rescorla's 1967 "truly random control"'), for example, yields a CS that is, at asymptote, associatively neutral despite occasional, or even frequent, CS-US pairings (e.g., Rescorla, 1966, 1968). The model explains this as the result of "blocking" by contextual stimuli (cf. Ayres, Benedict, \& Witcher, 1975). In such a situation, the CS does not become conditioned to the US, despite pairings, because the contextual stimuli acquire all the associative strength possible in this situation.
\end{abstract}

This conception of the effect of random US presentation yields a number of testable predictions. Presentation of the experimental context in the absence of reinforcement should extinguish the context and increase the effectiveness of CS-US pairings; this

Research was supported in part by Grant BNS-77-28161 from NSF to J. Bruce Overmier and by Grants BNS-77-22075 from NSF and HD-01136 and HD-0098 from NICHD to the Center for Research in Human Learning. Requests for reprints should be sent to J. Bruce Overmier, Department of Psychology, Elliott Hall, 75 E. River Road, University of Minnesota, Minneapolis, Minnesota 55455. prediction was tested and confirmed by Dweck and Wagner (1970). An alternative test was provided by Tomie (1976), who showed that the blocking effect of random US presentation was specific to the context in which the US presentation occurred. This also was taken to support the inference that randomly presented USs yield conditioning to the context in which they are presented. Another type of test was used by Odling-Smee (1975). Working with shock reinforcement, he noted that rats would be expected to avoid an excitatory context, given the opportunity, even in the absence of any concurrently present CSs or USs; this prediction was also confirmed.

Rescorla and Wagner's theory also predicts that contextual stimuli will gain associative strength in certain types of inhibitory conditioning paradigms. Specifically, if a CS - signals an absence of otherwise unpredictable reinforcement (e.g., Rescorla, 1966), Wagner and Rescorla (1972) predict that the experimental context will become excitatory. This prediction has received very little attention in the experimental literature.

We proposed to test for the conditioned associative properties of contextual stimuli, using the transfer of control technique. This paradigm has proved to be a remarkably robust and sensitive index of classical conditioning (Maier, Seligman, \& Solomon, 1969; Rescorla \& Solomon, 1967; Trapold \& Overmier, 1972). In this paradigm, a classically conditioned stimulus is tested for its efficacy in exerting control over a separately established operant baseline. In general, a classically conditioned stimulus for electric shock (CS+) will increase rates of responding on avoidance baselines, a classically conditioned stimulus for a period free from shock (CS-) will decrease response rate, and an associatively neutral stimulus (CS0) will have no effect (Bull \& Overmier, 1968; 
Rescorla, 1966; Rescorla \& LoLordo, 1965). Thus, excitatory contextual stimuli, if they are "detached" and superimposed upon an operant baseline, should facilitate responding on that baseline.

\section{METHOD}

\section{Subjects}

Thirty mongrel dogs (15 male, 15 female), weighing approximately 11-14 kg, were obtained from the University of Minnesota Research Animal Resources Unit. They were housed in individual cages with free access to food and water throughout the experiment. The dogs were assigned randomly to one of six equal-sized groups.

\section{Apparatus}

Two experimental units were used. Avoidance training and transfer testing took place within a standard dog shuttlebox (e.g., Overmier, Bull, \& Pack, 1971). This box consisted of two chambers $(122 \mathrm{~cm}$ long $\times 68 \mathrm{~cm}$ wide $\times 99 \mathrm{~cm}$ high) separated by an adjustable barrier fixed at approximately shoulder height for each dog. Photocells mounted on each side of the barrier were used to record the subject's crossing from one chamber to the other. The floor of each chamber was an aluminum shock grid $(3-\mathrm{cm}$ bars, $1.5 \mathrm{~cm}$ apart). A commutator shifted the polarity pattern of the bars 6 times $/ \mathrm{sec}$. The shuttlebox was illuminated continuously by a 15-W bulb mounted in the ceiling of each chamber. A $12.7 \times$ $17.8 \mathrm{~cm}$ double-cone speaker was also mounted in the ceiling of each chamber.

The second experimental unit, used for classical conditioning, was a standard Pavlovian hammock enclosed in a sound-attenuating cubicle (e.g., Overmier et al., 1971). The hammock consisted of reinforced sheet rubber. Holes were cut into the rubber so that the dog's legs extended downward, while its body rested in the hammock. The dog's legs were secured with nylon ropes, and $5.0 \times$ $7.5 \mathrm{~cm}$ metal electrodes, coated with electrode paste, were fastened to the dog's hind footpads. Two $12.7 \times 17.8 \mathrm{~cm}$ double-cone speakers were mounted in the ceiling of the cubicle, as was an 18-W light.

\section{Procedure}

The experiment consisted of three major phases: (1) avoidance training, (2) classical conditioning, and (3) testing of the classically conditioned stimuli.

For the first 3 days, the dogs were trained on a Sidman avoidance baseline (30-sec R-S, 5-sec S-S intervals) in the shuttlebox. On the first day, 6-mA .5-sec shocks were used; 8-mA .25-sec shocks were used in all other avoidance sessions. White noise (70 dB, re $.0002 \mathrm{dyn} / \mathrm{cm}^{2}$ ) was continuously present in the shuttlebox. All avoidance sessions lasted $1 \mathrm{~h}$.

In the second phase, 5 1-h classical conditioning sessions alternated with 4 baseline maintenance days in which dogs were run in the shuttlebox for $1 \mathrm{~h}$ on the standard Sidman schedule. On conditioning days, each dog was secured in the Pavlovian harness and administered $24 \quad 10-\mathrm{sec}$ CSs and a series of 3-mA $5-\mathrm{sec}$ shocks. For a random half of the dogs, the CS was a $760-\mathrm{Hz}$ tone; for the remaining half, it was a $10-\mathrm{Hz}$ flashing light. White noise (65 dB, re $.0002 \mathrm{dyn} / \mathrm{cm}^{2}$ ) was continuously present. The tone raised the ambient sound level to $68 \mathrm{~dB}$. Whichever stimulus was not used as the CS was continuously present throughout the conditioning session as one component of the experimental context. Thus, when the tone was serving as a CS, the flashing light was on continuously throughout the session. Both of these CS modality groups were subdivided randomly into three treatment groups that differed with respect to the contingency between the CS and US. In one group $\left(\mathrm{CS}^{\circ}\right)$, the $24 \mathrm{CSs}$ were presented randomly (mean interstimulus interval $=2.5 \mathrm{~min}$ ) with respect to 24 shocks (mean intershock interval $=2.5 \mathrm{~min})$. In a second group $(\mathrm{CS}+)$, the same series of CSs was presented and the same series of shocks was gen-
Table 1

Stimulus Events Experienced by Subjects Over the Course of Five Conditioning Sessions

\begin{tabular}{ccrccc} 
& \multicolumn{2}{c}{ Total Presentations } & & & Total \\
Group & CS & US & Pairings & P(US/CS) & P(US/CS) \\
\hline CS- & 120 & 96 & 0 & .00 & .20 \\
CS1 & 120 & 120 & 24 & .20 & .20 \\
CS+ & 120 & 24 & 24 & .20 & .00 \\
\hline
\end{tabular}

erated by the control equipment. This shock stream, however, was gated through a $30-\mathrm{sec}$ clock initiated by CS onset. Only shocks scheduled to occur within $30 \mathrm{sec}$ of CS onset were actually received by the animal. The third group (CS-) was just the converse: Only shocks that were not scheduled to occur within $30 \mathrm{sec}$ of CS onset were actually presented. The exact distribution of shocks relative to CSs varied randomly within each group. Table 1 specifies the events experienced by animals in the various groups. These parameters yield $\phi$-coefficients of contingency (see Gibbon, Berryman, $\&$ Thompson, 1974) of approximately $.0, .1$, and -.1, respectively.

On the 3 days following the fifth classical conditioning session, the conditioned response to the tone was tested by presenting it while the dog responded on the avoidance schedule in the shuttlebox. No tones were presented for the first $10 \mathrm{~min}$ of each session. Thereafter, eight 10-sec tones were presented to the subject (mean interstimulus interval $=6 \mathrm{~min}$; the tone raised the ambient sound level in the shuttlebox to $73 \mathrm{~dB}$ ). The changes in response rate during these probes were used as an index of classical conditioning. All tone tests took place in the absence of the flashing light.

\section{RESULTS}

Baseline response rates during the test sessions were similar across groups $[F(5,24)=1.86, p>.10]$. Responses during the 10 -sec tone tests and during the $10 \mathrm{sec}$ preceding each test were summed for each dog for each test day and were used to calculate the percent change in baseline response rate resulting from tone presentation. This index indicates excitatory effects when positive and inhibitory effects when negative. A 2 by 3 by 3 ANOVA (function of tone $\times$ CSUS contingency $\times$ test day) was used to analyze these scores. This analysis indicated that (1) all data were stable across test days (main effect of days and all interactions with this factor produced Fs less than 1.00 ), and (2) the effect of the tone depended upon both its function-context or $\mathrm{CS}$ - and the conditioning contingency [function $\times$ contingency interaction, $\mathrm{F}(2,24)=10.86, \mathrm{p}<.0005$ ]

Figure 1 shows the data from the three groups in which the tone had served as a CS. When it had predicted shock, the tone enhanced avoidance responding $[\mathrm{t}(24)=3.20, \mathrm{p}<.005]$. When it had predicted the absence of shocks, the tone CS suppressed avoidance responding $[\mathrm{t}(24)=3.33, \mathrm{p}<.005]$. After truly random conditioning, the CS had little effect $[t(24)=$ $-.22]$.

Figure 2 shows the effect of the tone after serving as a contextual stimulus. The tone enhanced avoidance responding only after serving as a contextual stimulus in the inhibitory paradigm $[\mathrm{t}(24)=2.40$, 
EFFECTS OF CS AS A FUNCTION OF PARADIGM

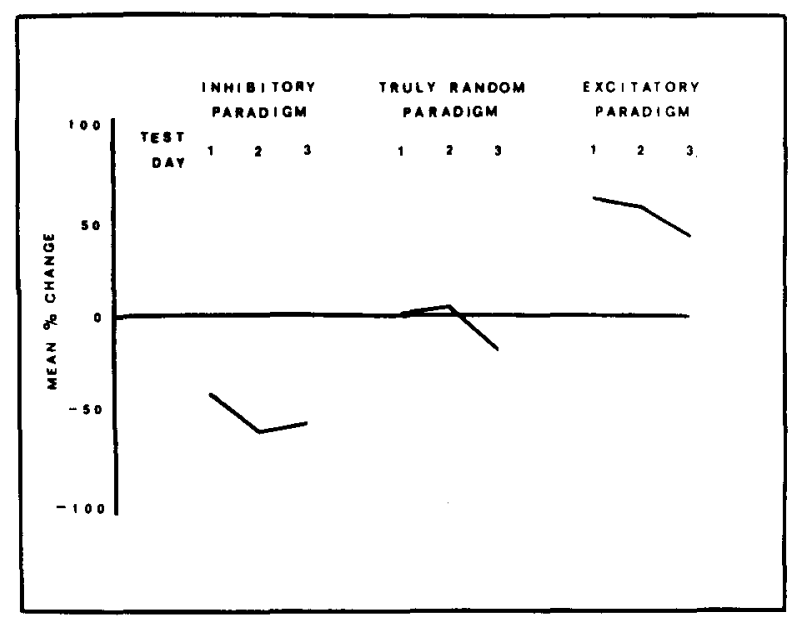

Figure 1. Changes in the avoidance baseline as a result of tone presentation after the tone had served as a CS.

EFFECTS OF CONIEXT AS A FUNCTION OF PARADIGM:

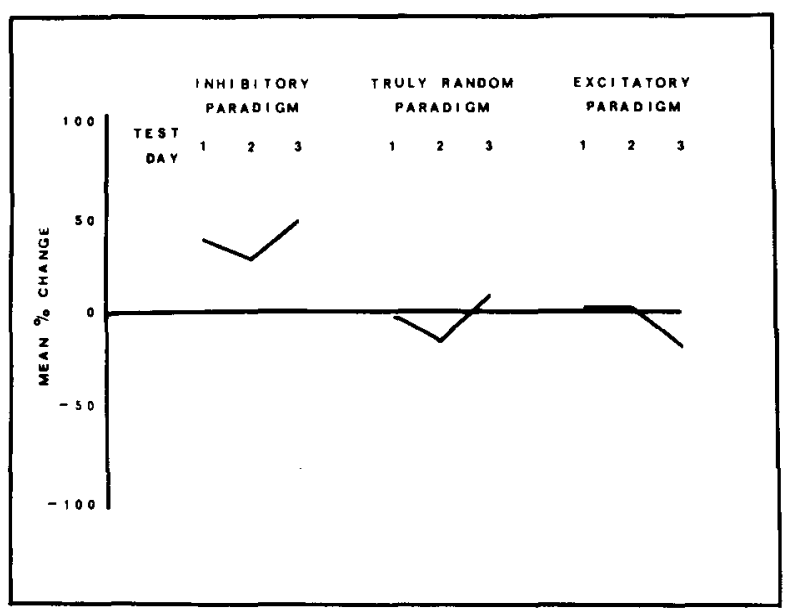

Figure 2. Changes in the avoidance baseline as a result of tone presentation after the tone had served as a component of the conditioning context.

$\mathrm{p}<.025$ ]. In contrast, the tone had little effect when it had been part of the background for either excitatory $[\mathrm{t}(24)=-.29]$ or truly random conditioning $[\mathrm{t}(24)=-.28]$.

\section{DISCUSSION}

The standard effects of aversive CSs upon avoidance responding were replicated. The $\mathrm{CS}+$ facilitated baseline responding both in absolute terms and relative to a truly random CS. Similarly, the CS- inhibited baseline both absolutely and relative to the random CS.

As predicted by Rescorla and Wagner's (1972) theory, the contextual stimuli in an inhibitory paradigm proved to be excitatory, as indicated by the effects on avoidance responding of the detachable background stimulus. This is one of the first confirmations of this prediction (see also Fanselow, 1980). In further agreement with the theory, contextual stimuli in the excitatory paradigm were associatively neutral. In contrast with theoretical expectations, the contextual stimulus from the truly random paradigm was not excitatory but, rather, was associatively neutral. Because the density of shock in the presence of the contextual cues alone was exactly equal in the inhibitory and truly random paradigms, the theory predicts that, at asymptote, these two contexts should be equally excitatory.

The CS data demonstrate that the tone stimulus was sensitive to classical conditioning contingencies. More critically, the successful demonstration of excitatory contextual associations to the tone component of the background in the inhibitory paradigm validates our technique for assessing the associative character of contextual stimuli. This result precludes any sort of simple attentional argument that would claim that other components of the complex of background stimuli were more salient than the tone test stimulus and thus overshadowed it. Similarly, this pattern of results also precludes an explanation in terms of generalization decrement to account for failure of the background tone to be excitatory. If the test stimulus were different enough from the experimental context to show the effects of generalization decrement in the truly random group, then the group that experienced the inhibitory paradigm should have shown a similar decrement when the contextual stimulus was tested, but it did not.

Several possible accounts of the absence of excitatory contextual associations in the truly random paradigm merit consideration. A variety of experiments (e.g., Ayres, Benedict, \& Witcher, 1975; Keller, Ayres, \& Mahoney, 1977; Rescorla, 1972) have shown that the neutrality of a CS1 and, presumably, the associated contextual excitation hold only asymptotically. Preasymptotically, both theory and data indicate that the CS1 may acquire temporary associative strength due to random CS-US pairings. In such a situation, the truly random context might be less excitatory than the context in the inhibitory paradigm because the CSI would be controlling part of the available associative strength. However, this cannot be the case in the present study since the explicit tests of the CS1 demonstrate that our extended training did, in fact, yield a neutral CS1. Thus, all available associative strength should have accrued to the context, and, since the density of reinforcement during the context (in the absence of the CS) was equal in the inhibitory and truly random paradigms, the contexts should have been equally excitatory.

One might question any performance-based index of background association. Baker and Mackintosh (1979), for example, suggest that "it may be that long stimuli that take up relatively large proportions of 
the experimental session (and the context is certainly composed of such stimuli) control as much fear as shorter stimuli, but that this fear is not mapped on to suppression in the same manner"' (p. 292). There are at least two problems with this suggestion. First, in the absence of a consistent theoretical account of the differential learning/performance mapping, this amounts to little more than a restatement of the results. Second, the presence of measurable background excitation in the inhibitory paradigm indicates that, at least in this instance, learning about the context does map fairly directly onto transfer of control performance.

Another view would suggest a habituation mechanism as a result for the absence of excitatory background associations in the truly random paradigm. This account is of particular interest given the increasing role of contextual cues in theories of habituation (Schull, 1979; Wagner, 1976) and the alternative accounts of apparent "contextual blocking" that these theories provide (see Randich \& LoLordo, 1979; Scoles, Note 1). Such accounts would suggest that our contextual cue was not associated with shock, because the animal habituated to the shocks and thus was not effectively reinforced. Such habituation might operate via nonassociative (Kamin, 1961; Solomon \& Corbit, 1974) or associative (Schull, 1979; Wagner, 1976) mechanisms. However, any such accounts would also seem to predict that animals would habituate to the shocks in the inhibitory paradigm and thus not support excitatory conditioning to the contextual tone there either; but, again, this was not the case.

In short, we are unaware of any current theory that would account for the disparity between contextual associations in the inhibitory and truly random paradigms. Since contextual stimuli are highly correlated with the reinforcer in both paradigms, contemporary conditioning theories would seem to predict that they would be excitatory in both cases (cf. Mackintosh, 1973; Rescorla \& Wagner, 1972; Wagner, 1978).

Some parametric considerations lead us to suggest that a nonassociative stress effect may be interacting with the expected associative effects. To insure that our experimental manipulation was sufficiently powerful, we used shock parameters considerably more severe (e.g., 120 5-sec shocks in the truly random group) than those in common usage. Furthermore, the truly random paradigm was the most stressful of the three conditioning paradigms, since dogs in this group received more shocks and since completely unpredictable shocks (i.e., unsignaled shocks with no signaled safety periods) are known to be more stressful than predictable shocks (e.g., Weiss, 1971; see Weinberg \& Levine, 1980, for a review). There is a considerable theoretical (e.g., Bruner, Matter, \& Papanek, 1955; Tolman, 1948) and empirical (e.g., Johnson, 1953; Spence \& Lippit, 1940) literature that suggests that, in circumstances of extreme stress, an organism narrows its attentional field to the most salient cues in the environment (for reviews, see Easterbrook, 1959; Melton, 1950; Thistlethwaite, 1951). Other cues, such as some contextual ones, may be functionally ignored and thus may not gain associative strength even when they are correlated with reinforcement. Thus, our failure to find evidence for contextual associations in the truly random paradigm could be due to an attentional factor, but one that was operative only in that very stressful paradigm. Since the inhibitory paradigm was less stressful (fewer and more predictable shocks), the attentional fields that the dogs brought to bear were apparently wide enough to encompass our manipulable background cue.

The notion of a stress-elicited attentional deficit could also reconcile our findings with others in the literature. To our knowledge, all previous successful demonstrations of contextual association (e.g., Dweck \& Wagner, 1970; Fanselow, 1980; Odling-Smee, 1975, 1978; Tomie, 1976) have used parameters that were almost certainly less stressful than ours. Thus, we would expect any attentional deficits to be relatively minimal. Second, all have used tests that relied upon presentation of the entire conditioning context rather than on a single component of it. Such tests would be completely insensitive to any effects of selective attention.

While this account is frankly speculative, it is also amenable to a straightforward empirical test: Decreasing the stressfulness (e.g., by decreasing shock duration, number, or intensity) should increase the probability that the manipulable background cue will be attended to and hence increase the associative strength that accrues to it in the truly random paradigm. Similarly, increasing stress within the inhibitory paradigm should, on this account, decrease the background effects as assessed by a transfer of control test. As a rule, of course, increasing the strength of reinforcement enhances conditioning effects. We are suggesting that when this reinforcement is aversive and selective attention may be operative, this function is, in fact, an inverse U (cf. Yerkes \& Dodson, 1908).

Although this is one of the first disconfirmations of predicted contextual effects and one that stands in opposition to several previous studies, we see it as a result of considerable significance for two reasons. First, the transfer of control technique has a long and successful history in the assessment of classical associations and is embedded in a relatively firm theoretical and empirical network (Maier, Seligman, \& Solomon, 1969; Rescorla \& Solomon, 1967). This is in contrast with other measures of contextual association, such as the ability of background stimuli to block conditioning to a CS (Dweck \& Wagner, 1970; Tomie, 1976), which are rather less direct, of more recent origin, and rest on theory that is still developing (cf. Dickinson, Hall, \& Mackintosh, 1976; Randich 
\& LoLordo, 1979; Scoles, Note 1; Popik \& Frey, Note 2). Second, to our knowledge, this is the first assessment of contextual association that has investigated the construct over the full range of conditioning paradigms. Our replication of basic CS effects and the production of two predicted context effects suggest that our methodology is adequate for producing and detecting classical associations. This broad base of expected effects highlights the single unexpected one: Apparently, contextual stimuli are not always excitatory after truly random presentations of CSs and USs.

\section{REFERENCE NOTES}

1. Scoles, M. T. An evaluation of the context blocking account of the UCS-pre-exposure phenomenon in classical fear conditioning. Paper presented at the meeting of the Midwestern Psychological Association, May 1980.

2. Popik, R. S., \& Frey, P. W. Retarding effect of unsignalled shock presentations: Potential mediation by background stimuli. Paper presented at the meeting of the Midwestern Psychological Association, May 1978.

\section{REFERENCES}

Ayres, J. J. B., Benenict, J. O., \& Witcher, E. S. Systematic manipulation of individual events in a truly random control in rats. Journal of Comparative and Physiological Psychology, 1975, 88, 97-103.

Baker, A. G., \& Mackintosh, N. J. Preexposure to the CS alone, US alone, or CS and US uncorrelated: Latent inhibition, blocking by context or learned irrelevance? Learning and Motivation, 1979, 10, 278-294.

Bruner, J. S., Matter, J., \& Papanek, M. L. Breadth of learning as a function of drive level and mechanization. Psychological Review, 1955, 62, 1-10.

Bull, J. A., \& Overmier, J. B. Additive and subtractive properties of excitation and inhibition. Journal of Comparative and Physiological Psychology, 1968, 66, 511-514.

Dickinson, A., Hall, G., \& Mackintosh, N. J. Surprise and the attenuation of blocking. Journal of Experimental Psychology: Animal Behavior Processes, 1976, 2, 313-322.

DWeck, C. S., \& W AGner, A. R. Situational cues and the correlation between CS and US as determinants of the conditioned emotional response. Psychonomic Science, 1970, 18, 145-147.

EASTE RBROOK, J. A. The effect of emotion on cue utilization and the organization of behavior. Psychological Review, 1959, 66, 183-201.

FANSE LOW, M. S. Signalled shock-free periods and preference for signalled shock. Journal of Experimental Psychology: Animal Behavior Processes, 1980, 6, 65-80.

Gibion, J., Berryman, R., \& Thompson, R. L. Contingency spaces and measures in classical and instrumental conditioning. Journal of the Experimental Analysis of Behavior, 1974, 21, 585-605.

Johnson, E. E. The role of motivational strength in latent learning. Journal of Comparative and Physiological Psychology, 1953, 45, 526-530.

Kamin, L. J. Apparent adaptation effects in the acquisition of a conditioned emotional response. Canadian Journal of Psychology, 1961, 15, 176-188.

Keller, R. J., Ayres, J. J. B., \& Mahoney, W. J. Brief versus extended exposure to truly random control procedures. Journal of Experimental Psychology: Animal Behavior Processes, 1977, 3, 53-65.

LoLondo, V. M. Classical conditioning: Compound CSs and the Rescorla-Wagner model. In M. Bitterman, V. LoLordo, J.
Overmier, \& M. Rashotte, Animal learning. New York: Plenum Press, 1979.

Mackintosh, N. J. Stimulus selection: Learning to ignore stimuli that predict no change in reinforcement. In $\mathbf{R}$. Hinde \& J. Stevenson-Hinde (Eds.), Constraints on learning. New York: Academic Press, 1973.

Maien, S. F., Seligman, M. E. P., \& Solomon, R. L. Pavlovian fear conditioning and learned helplessness: Effects on escape and avoidance behavior of (a) the CS-US contingency, and (b) the independence of the US and voluntary responding. In B. Campbell \& R. Church (Eds.), Punishment and aversive behavior. New York: Appleton-Century-Crofts, 1969.

MCAllister, W. R., \& MCAllister, D. E. Behavioral measurement of conditioned fear. In F. Brush (Ed.), Aversive conditioning and learning. New York: Academic Press, 1971.

Melton, A. W. Learning. Annual Review of Psychology, 1950, 1, 9-30.

Odling-Smee, F. J. The role of background stimuli during Pavlovian testing. Quarterly Journal of Experimental Psychology, 1975, 27, 201-209.

Odling-SmeE, F. J. The overshadowing of background stimuli: Some effects of varying amounts of training and UCS intensity. Quarterly Journal of Experimental Psychology, 1978, 30, 737-746.

Overmier, J. B., Bull, J. A., \& PaCk, K. On instrumental response interaction as explaining the influences of Pavlovian CSs upon avoidance behavior. Learning and Motivation, 1971, 2, 103-112.

Randich, A., \& LoLordo, V. M. Associative and nonassociative theories of the UCS preexposure phenomenon: Implications for Pavlovian conditioning. Psychological Bulletin, 1979, 86, 523-548.

Rescorla, R. A. Predictability and number of pairings in Pavlovian fear conditioning. Psychonomic Science, 1966, 4, 383-384.

Rescorla, R. A. Pavlovian conditioning and its proper control procedures. Psychological Review, 1967, 74, 71-80.

RESCORLA, R. A. Probability of shock in the presence and absence of CS in fear conditioning. Journal of Comparative and Physiological Psychology, 1968, 66, 1-5.

Rescorla, R. A. Informational variables in Pavlovian conditioning. Psychology of Learning and Motivation, 1972, 6, 1-46.

RESCORLA, R. A., \& LoLondo, V. M. Inhibition of avoidance behavior. Journal of Comparative and Physiological Psychology, 1965, 59, 406-412.

Rescorla, R. A., \& Solomon, R. L. Two-process learning theory: Relationships between Pavlovian conditioning and instrumental learning. Psychological Review, 1967, 74, 151-182.

Rescorla, R. A., \& Wagner, A. R. A theory of Pavlovian conditioning: Variations in the effectiveness of reinforcement and nonreinforcement. In A. Black \& W. Prokasy (Eds.), Classical conditioning II: Current research and theory. New York: Academic Press, 1972.

Schull, J. A conditioned opponent theory of Pavlovian conditioning and habituation. Psychology of Learning and Motivation, 1979, 13, 57-90.

Solomon, R. L., \& Corbit, J. D. An opponent-process theory of motivation: I. Temporal dynamics of affect. Psychological Review, 1974, 81, 119-145.

SPENCE, K. W., \& LiPPIT, R. "Latent" learning of a simple mazi problem with relevant needs satiated. Psychological Bulletin, 1940, 37, 429. (Abstract)

Thistlethwaite, D. A critical review of latent learning and related experiments. Psychological Bulletin, 1951, 48, 97-129.

Tolman, E. C. Cognitive maps in rats and men. Psychological Review, 1948, 55, 189-208.

Tomie, A. Retardation of autoshaping: Control by contextual stimuli. Science, 1976, 192, 1244-1245.

Tra Pold, M. A., \& Overmier, J. B. The second learning process in instrumental learning. In A. Black \& W. Prokasy (Eds.), Classical conditioning II: Current research and theory. New York: Appleton-Century-Crofts, 1972 
WAGNer, A. R. Priming in STM: An information processing mechanism for self-generated or retrieval-generated depression in performance. In T. Tighe \& R. Leaton (Eds.), Habituation: Perspectives from child development, animal behavior, and neurophysiology. Hillsdale, N.J: Erlbaum, 1976.

WAGNER, A. R. Expectancies and the priming of STM. In S. Hulse, H. Fowler, \& W. Honig (Eds.), Cognitive processes in animal behavior. Hillsdale, N.J: Erlbaum, 1978.

Wagner, A. R., \& Rescorla, R. A. Inhibition in Pavlovian conditioning: Application of a theory. In R. A. Boakes \& S. M. Halliday (Eds.), Inhibition and learning. London: Academic Press, 1972.
Weinberg, J., \& Levine, S. Psychobiology of coping in animals: The effects of predictability. In S. Levine \& H. Ursin (Eds.), Coping and health. New York: Plenum Press, 1980.

Werss, J. M. Effects of coping behavior in different warning signal conditions on stress pathology in rats. Journal of Comparative and Physiological Psychology, 1971, 77, 1-13.

YERKES, R. M., \& DoDson, J. D. The relation of strength of stimulus to rapidity of habit-formation. Journal of Comparative and Neurological Psychology, 1908, 18, 458-482.

(Received for publication September 16, 1980; revision accepted April 8, 1981.) 